\title{
A Review of Animal Intrusion Detection System
}

\author{
S Jeevitha \\ Research Scholar: \\ Dept of Computer Application \\ Bharathiyar University Coimbatore, India
}

Dr SNS Rajalakshmi College of Arts and Science College,

\begin{abstract}
Image processing and IoT sensor monitoring network technology has taken the evolutions of sensors to a completely different level. The conflicts between human and animal become a major problem in the agriculture field and in the forest zone which leads to human life in danger and also losing a huge quantity of resources. To solve this problems animal intrusion alert system can be used with wireless sensors and sends an automatic alert message to the landowner also to forest officials with an image. This can make early warning notification to take a suitable action depends on the type of intruder. The sensor will detect the movement of the animal and the camera will capture the image, using image processing techniques the captured image is classified via a microcontroller, then GSM module will send the alert notification SMS to the forest department or the landowner. This survey is used to understand various steps, tools, and experimental setups to save human life from animal intrusion.
\end{abstract}

Keywords - IoT (Internet of Thing), Sensors, Image processing, Microcontroller, GSM module.

\section{INTRODUCTION}

Deforestation, lack of natural prey and habitat loss has forced wild animals to live closely with human settlement prey on domestic livestock. So animals are started attacking humans for theirs food. Compared with other tiger, elephant entry are in extreme form of conflict and responsible for killing human's lives in India .Due to human and animal conflict and increase in population humans started demolishing the forest for their existence these leads to harm animals and its habitats. Animals started entering nearby villages due to the rapid growth of industrialization in forest areas. Losing subsistence and dryness makes them raving mad and pretend to attack crops, livestock, sometimes human and farming lands. Usually, farmers use the electrical fence to protect the field from animals which cause electrocution with cramp makes them behave unusual manner. The safety of animal and human is identically important. To overcome this problem an intelligent monitoring system is required to monitor automatically and recognize the image of animal entry and gives an alert message to human. This survey paper is based on various wired and wireless applications used to alert human from animal intrusion. Researches regarding animals in image processing have been an important field for numerous applications [6]. IoT (Internet of Thing) becomes a recent emerging technique all over the world. It furnishes the capabilities with a large number of applications, only a few are currently applicable to our society.

Wireless applications would likely improve the quality of our day to day activity in many domains and environment such as for emergency responses, intrlligent control, and military purpose [4]. Many approaches involving to sense animal entry using IoT, sensing unit, communicating

\author{
Dr. Venkatesh Kumar
}

Assistant Professor:

Dept of Computer Application

Dr SNS Rajalakshmi College of Arts and Science College, Bharathiyar University Coimbatore, India

device to take preliminary actions, diversion of animal and sending alert to farmers. Various methods and algorithms have been developed to enhance the safety measure from animal intrusion. This paper presents the reviews for animal detection methods using digital image. Sensor-based applications are used for various fields which are real-life applications. Features of using this device may reduce cost, robustness, reliable, easy access by farmers, and remote monitor with lower energy consumption. Below given methods are used to detect animal from intrusion.

Table 1: Methods of animal intrusion detection

\begin{tabular}{|l|l|}
\hline Methods & Detection techniques \\
\hline Electric Fences & $\begin{array}{l}\text { Detection using Wheatstone bridge principle } \\
\text { (Circuit setup). }\end{array}$ \\
\hline Artificial Repellents & $\begin{array}{l}\text { Detection using Odour \& color based electronic } \\
\text { repellents. }\end{array}$ \\
\hline Acoustic System & Scare animals by use of sound predators. \\
\hline $\begin{array}{l}\text { Microcontroller } \\
\text { based system }\end{array}$ & $\begin{array}{l}\text { Once intrusion found the buzzer will activate and } \\
\text { send message alert to the farmers. }\end{array}$ \\
\hline $\begin{array}{l}\text { Intrusion detection } \\
\text { system using } \\
\text { Raspberry PI }\end{array}$ & Automatic highly efficient detection method. \\
\hline
\end{tabular}

\section{A. OVERVIEW OF EXISTING ANIMAL INTRUSION}

\section{ALERT SYSTEM:}

The review of literature is one of the major parts of any research work. The word "review" indicates the animal intrusion alert system, and a detailed study of the IoT based applications and how it is to be researched. These papers sustain the information about the research and surveys about the work done on the specific task. Different approaches used to track, monitor, and recognize animals in various scenarios with wired and wireless sensor-based IoT (Internet of Thing) applications.

Yu et al 2013 [1] have proposed an automated species recognition method using local cell-structured LBP (Local Binary Pattern) feature and global dense SIFT (Scaleinvariant Feature Transform) descriptor for feature extraction and improvise (ScSPM) sparse coding spatial pyramid matching to extract dense SIFT descriptor and cell-structured LBP as a local feature. Global features generate max pooling and weighted sparse coding using multi-scale pyramid kernel. Support vector machine algorithm classifies and tests the dataset contains 18 species from the field of two different sites. This method achieves around $82 \%$ accuracy on realtime animal identification even in complex scenarios.

Radhakrishnan et al 2018[2] proposed animal intrusion detection system based on image processing and 
machine learning approach. The image of an animal is segmented using a watershed algorithm to extract various objects in the image and to examine that if any threat animal is found in segmentation. This algorithm is to create a barrier which is the contour only when the marked region meets different markers. Gabor filter is extensively used in extracting a region with text to recognize facial expression in various frequencies. Linear SVM is a supervised learning algorithm to train the dataset and to classify text and hypertext. This method of animal intrusion detection achieves an overall average of around $54.32 \%$.

Kiran et al 2018[3] proposed IOT- based animal intrusion detection system. PIR (Passive infrared sensor) detects the movement and triggers the camera to take the animal image, once the animal is detected by the sensor the signal is passed to the camera via a microcontroller Arduino Uno. The image is classified with the sample images which is stored in the database. When the wild animal is identified as elephant the bright light emitted is used and if leopard is identified then a loud noise is used to divert it. Consequently, alert SMS is sent to the forest officials and the landowners using GSM module.

Santhoshi et al 2018[4] proposed intrusion recognition in farmland through a wireless sensor network (WSN) technology. The motion sensor is placed at various locations to sense the movement and communicate to the organizer via Radio frequency transceiver. The detection raise then the organizer sends an alert call to the farm owner mobile through the Global System for Mobile (GSM) module. An Arduino board is fixed near the centralized sensor and the GSM module will be the interface along with buzzers and RFID transmitter. To differentiate authorized and unauthorized entries in farmland Radio-frequency identification (RFID) tags are used.

Sambhaji et al 2019[5] proposed an IOT based harmful animal early warning system. At first, stored the harmful animal database in the computer system or cloud which is already connected to the IoT model with various sensors. Images are captured with a web camera only if any movement of animal found in the school area, the computer system will compare the moving image with stored database image and triggers the Ardunio Uno for the programming process. It buzzes the alarm also send SMS on a user's mobile phone after the animal is detected.

Sheela et al 2016[6] proposed low cost alert system to monitor animals using IOT devices. The PIR sensor tower consists of Raspberry Pi module which is connected to a USB camera to capture images at the time of motion is sensed and sends images via a web server using internet. For image processing Open $\mathrm{CV}$ is installed on raspberry pi also in this paper, to reduce the cost of electric lines solar power is fixed in each sensor tower the solar panel will charges the battery from the sunlight and provides power to the sensor tower. This provides power consumption low and stores battery power even at night.

Andavarapu et al 2017[7] proposed Weighted Cooccurrence Histograms of Oriented Gradients (W-CoHOG) feature vector to recognize animal. Histogram equalization is performed to reduce noise, distortions and to enhance the highlighted region of interest. The gradients are calculated in magnitude and direction is represents to convert into eight orientations. Sliding window techniques identify animals in different sizes with zoom level of the camera. The proposed algorithm was developed in Python - OpenCV with two Benchmark Dataset and LIBLINEAR classifier was used for classification.

Trnovszky et al 2017[8] proposed animal recognition approach based on CNN. To minimize the effect of factors the input image can be treated with a series of preprocessing techniques. A well-known image recognition method is used to recognize computed phase such as Principal Component Analysis (PCA), Linear Discriminant Analysis (LDA), and Local Binary Pattern Histograms (LBPH). Proposed CNN and SVM classification method have been successfully identify animal faces from the created animal database, Convolutional Neural Network (CNNs) are a category of Neural Networks that have been effectively recognize animal than SVM classifiers. CNNs achieves overall best precision accuracy of $97 \%$, various tested methods were implemented in MATLAB and C++/Python Programming language.

Xue et al 2017[9] proposed a wireless sensor network based on UWB technology. To deploy intrusion detection by analyzing the Ultra Wide Band (UWB) signals, the collected signal is reconstructed the phase space to show its characteristic. Then the automatic feature extraction of CNN (convolutional Neural Network) is to find out the difference between intrusions of species. The attributes are automatically referred into different classifiers to detect intrusions and achieves nearly $16 \%$ accuracy more than existing feature extraction.

Upadrashta et al 2015[10] developed a Passive Infra-Red (PIR) sensor to detect animal intrusion detection system takes on the form of a sensor-tower platform (STP) and was developed in-house. Data was created through the animation-based simulation process, based on chirplet-based decomposition SVM classifier utilizes a feature vector and achieves average accuracy in excess of $94 \%$.

Roy et al 2015[11] proposed a prototype for intrusion detection in agriculture field using WSN (wireless sensor network). AVR -Microcontroller based wireless sensor boards were equipped with two sensors- PIR to sense the movement of human or animal and Ultrasonic determines the distance of object, when the intruder enters into the field the sensor board will transmit a detection message to the sink with the help of Zigbee. GSM module is used to generate alarm and SMS notification to the farmer.

Roomi et al 2010[12] proposed automatic intrusion detection method using vision based technology. Detection method is processed by low cost and fast implementation for segmentation followed by star skeletonization algorithm. A novel Line Model approach is developed to match the resulting skeleton of the object. Alarm is generated when the monkey is detected if it is in upright posture. In background updated frame the present object may detect as monkey or human using MATLAB environment. Table 1 shows existing image processing animal intrusion detection system and Table 2 shows existing sensor based animal intrusion detection system. 
Table 2: Existing animal intrusion system using image processing techniques

\begin{tabular}{|c|c|c|c|c|}
\hline Objectives & $\begin{array}{c}\text { Feature } \\
\text { Extraction }\end{array}$ & Classifier & Author & Year \\
\hline $\begin{array}{l}\text { Recognize } \\
\text { animal }\end{array}$ & W-CoHOG & LIBLINEAR & $\begin{array}{l}\text { Andavarapu et } \\
\text { al [7] }\end{array}$ & 2017 \\
\hline $\begin{array}{l}\text { Intrusion } \\
\text { detection }\end{array}$ & $\begin{array}{l}\text { Chirplet-based } \\
\text { decomposition \& } \\
\text { Cross Correlation }\end{array}$ & $\begin{array}{l}\text { SVM (Support } \\
\text { Vector } \\
\text { Machine) }\end{array}$ & $\begin{array}{l}\text { Upadrashta et } \\
\text { al }[10\end{array}$ & 2015 \\
\hline $\begin{array}{l}\text { Intrusion } \\
\text { detection }\end{array}$ & $\begin{array}{l}\text { CNN } \\
\text { (Convolutional } \\
\text { Neural Network) }\end{array}$ & - & Xue et al[9] & 2017 \\
\hline $\begin{array}{l}\text { Animal } \\
\text { recognition }\end{array}$ & \begin{tabular}{lr} 
LBP & (Local \\
Binary Pattern) \& \\
SIFT (Scale- \\
invariant \\
\multicolumn{2}{c}{ Feature } \\
Transform)
\end{tabular} & $\begin{array}{l}\text { (SVM) Support } \\
\text { Vector } \\
\text { Machine. }\end{array}$ & Yu et al[1] & 2013 \\
\hline $\begin{array}{l}\text { Animal } \\
\text { intrusion } \\
\text { detection } \\
\end{array}$ & Gabor Filter & $\begin{array}{l}\text { SVM) Support } \\
\text { Vector } \\
\text { Machine } \\
\end{array}$ & $\begin{array}{l}\text { Radhakrishnan } \\
\text { et al [2] }\end{array}$ & 2018 \\
\hline $\begin{array}{l}\text { Animal } \\
\text { recognition } \\
\text { approach }\end{array}$ & $\begin{array}{ll}\text { PCA, } & \text { LDA, } \\
\text { LBPH }\end{array}$ & $\begin{array}{l}\text { (SVM) Support } \\
\text { Vector } \\
\text { Machine, CNN } \\
\text { (Convolutional } \\
\text { Neural } \\
\text { Network) }\end{array}$ & $\begin{array}{l}\text { Trnovszky et } \\
\text { al [8] }\end{array}$ & 2017 \\
\hline
\end{tabular}

Table 3: Existing Sensor based animal intrusion detection

\begin{tabular}{|c|c|c|c|c|}
\hline Objectives & Sensors & Microcontroller & Author & Year \\
\hline $\begin{array}{l}\text { Intrusion } \\
\text { detection in } \\
\text { Agriculture } \\
\text { field }\end{array}$ & $\begin{array}{lr}\text { PIR \& } \\
\text { Ultrasonic }\end{array}$ & $\begin{array}{l}\text { AVR } \quad \text { Advance } \\
\text { Virtual RISC }\end{array}$ & $\begin{array}{l}\text { Roy et al } \\
{[11]}\end{array}$ & 2015 \\
\hline $\begin{array}{ll}\text { IOT- based } \\
\text { intrusion } \\
\text { detection } \\
\text { system }\end{array}$ & $\begin{array}{l}\text { Passive } \\
\text { infrared } \\
\text { sensor }\end{array}$ & $\begin{array}{l}\text { Arduino Uno \& } \\
\text { Arduino IDE }\end{array}$ & $\begin{array}{ll}\text { Kiran } & \text { et } \\
\text { al [3] } & \end{array}$ & 2018 \\
\hline $\begin{array}{l}\text { Intrusion } \\
\text { recognition }\end{array}$ & $\begin{array}{l}\text { Motion } \\
\text { sensor }\end{array}$ & Arduino & $\begin{array}{l}\text { Santhoshi } \\
\text { et al[4] }\end{array}$ & 2018 \\
\hline $\begin{array}{l}\text { Animal } \\
\text { intrusion early } \\
\text { warning system }\end{array}$ & & Arduino Uno & $\begin{array}{l}\text { Sambhaji } \\
\text { et al [5] }\end{array}$ & 2019 \\
\hline $\begin{array}{l}\text { Low cost alert } \\
\text { system }\end{array}$ & - & Raspberry Pi & $\begin{array}{l}\text { Sheela et } \\
\text { al [6] } \\
2016\end{array}$ & 2016 \\
\hline
\end{tabular}

\section{REFERENCES}

[1] Xiaoyuan Yu, Jiangping wang, Roland Kays, Patrick A Jansen, Tianjiang Wang and Thomas Huang, "Automated identification of animal species in camera trap images", EURASIP "Journal on Image and Video Processing", 2013.

[2] Saieshwar Radhakrishana, Ramanathan R, “ A Support Vector Machine with Gabor Features for Animal Intrusion Detection in Agriculture Fields", 8th International Conference on Advances in Computing and Communication, "Elsevier Procedia Computer Science 143", pp 493501, 2018.

[3] Divya, Usha Kiran, Praveen M, "IOT- Based Wild Animal Intrusion Detection System", "International Journal on Recent and Innovation Trends in Computing and Communication", 2321-8169, Volume: 6, Issue: 7, pp: 06-08, 2018.

[4] Santhoshi K. Jai, S. Bhavan, "Intruder recognition in a farm through wireless sensor network", "International Journal of Advance Research, Ideas and Innovations in Technology", ISSN: 2454-132X, Volume 4, Issue 3, pp : $667-669,2018$.

[5] Sahane Pradnya Sambhaji, Salunke Nikita Sanjiv, Shirsath Vitthal Somnath , Shukla Shreyas Sanjay , Prof. A. R. Panhalka, "Early Warning System for Detection of Harmful Animals using IOT" , "International Journal of Advance Research and Innovative ideas", ISSN(O)-2395-4396, Vol-5 Issue-3, 2019.

[6] Sheela.S, Shivaram. K. R, Chaitra. U, Kshama. P, Sneha. K.G, Supriya K.S, "Low Cost Alert System for Monitoring the Wildlife from Entering the Human Populated Areas Using IOT Devices", "International Journal of Innovative Research in Science, Engineering and Technology", ISSN : 2319-8753, Vol. 5, Special Issue 10, 2016.

[7] Nagaraju Andavarapu, Valli Kumari Vatsavayi, "Wild-Animal Recognition in Agriculture Farms Using W-COHOG for AgroSecurity", "International Journal of Computational Intelligence Research”, ISSN 0973-1873 Volume 13, pp. 2247-2257, 2017.

[8] Tibor Trnovszky, Patrik Kamencay, Richard Orjesek, Miroslav Benco, Peter Sykora, "Animal Recognition System Based On Convolutional Neural Network", "Digital Image Processing And Computer Graphics", Vol. 15, 2017

[9] Wenling Xue, Ting Jiang, Jiong Shi, “Animal Intrusion Detection Based on Convolutional Neural Network", "17th International Symposium on Communications and Information Technologies", 2017.

[10] Raviteja Upadrashta, Tarun Choubisa, V. S. Aswath, A. Praneeth Ajit Prabhu, Siddhant Raman, Tony Gracious, P. Vijay Kumar, "An Animation-and-Chirplet Based Approach to Intruder Classification using PIR Sensing", "IEEE Tenth International Conference on Intelligent Sensors, Sensor Networks and Information Processing (ISSNIP) Singapore", pp: 7-9, 2015.

[11] Sanku Kumar Roy, Arijit Roy, Sudip Misra," AID: A Prototype for Agricultural Intrusion Detection Using Wireless Sensor Network", "IEEE Communication Software, Services and Multimedia Applications Symposium”, pp: 7059- 7064, 2015.

[12] Mansoor Roomi S, Rajesh P, Joythi Priya R, Senthilarasi M, "A Line Model Based Approach For Monkey Intrusion Detection”, “ IEEEInstitute of Electrical and Electronics Engineers", 2010. 